J. Materials Sci. Vol. 42, 2007, 7049-7051

\title{
The Fracture and Fatigue Behaviour of Nano-Modified Epoxy Polymers
}

\author{
B.R.K. Blackman, A.J. Kinloch, J. Sohn Lee and A.C. Taylor \\ Department of Mechanical Engineering, South Kensington Campus, Imperial College London, \\ London SW7 2AZ, U.K.
}

R. Agarwal

Henkel Corporation, 32100 Stephenson Highway, Madison Heights, MI 48071, USA

G. Schueneman

Henkel Corporation, 1001 Trout Brook Crossing, Rocky Hill, CT 06067, USA

\section{S. Sprenger}

Nanoresins AG, Charlottenburger Strasse 9, 21502 Geesthacht, Germany

(a.kinloch@imperial.ac.uk)

Key words: adhesives, epoxy polymers, fatigue, nano-materials, rubber-toughened.

\section{Introduction}

When polymerised, epoxy adhesives are amorphous and highly-crosslinked (i.e. thermosetting) materials. This microstructure results in many useful properties for structural engineering applications, such as a high modulus and failure strength, low creep, and good performance at elevated temperatures. However, the structure of such thermosetting polymers also leads to one highly undesirable property in that they are relatively brittle materials, with a poor resistance to crack initiation and growth. Nevertheless, it has been well established [e.g. 1-3] for many years that the incorporation of a second micro-phase of dispersed rubbery particles into the epoxy polymer can greatly increase their toughness, without significantly impairing the other desirable engineering properties. Typically the rubber particles are about 1 to $5 \mu \mathrm{m}$ in diameter with a volume fraction of about 5 to 20\%. More recently there has emerged a new technology which holds great promise for increasing further the mechanical performance of such multiphase thermosetting polymers. Namely, via the additional formation of a nano-phase structure in the 
polymer, where the nano-phase consists of small rigid particles of silica [4-9], as shown in Figure 1. Now, the maximum toughness of the nano-silica modified epoxy polymers is not usually as great as that achieved using a rubbery second-phase. However, it has been found that the combination of both rubber particles and silica nano-particles, to give a 'hybrid' modified epoxy, can give a synergistic toughening effect [5-7], where the measured toughness is greater than would be predicted by simple addition of the individual toughening increments due to the presence of the particles.

The present paper addresses the behaviour of nano-silica modified epoxy polymers when subjected to cyclic-fatigue loading. This is relevant to the development of multiphase polymers since an increase in the initial toughness via previous technologies is often achieved without any significant improvement in the corresponding cyclic-fatigue behaviour of the material. Further, design engineers would clearly prefer both the initial toughness and the long-term cyclic-fatigue properties to be significantly enhanced by the presence of the toughening phase in the epoxy polymer.

\section{Experimental}

The materials were based upon a one-component hot-cured epoxy formulation. The epoxy resin was a standard diglycidyl ether of bisphenol A (DGEBA). The nano-particles of silica $\left(\mathrm{SiO}_{2}\right)$ were obtained at a concentration at 40wt.\% in a DGEBA epoxy resin: 'Nanopox F400' from Nanoresins, Geesthacht, Germany. The surface-modified $\mathrm{SiO}_{2}$ nano-particles had an average particle size of about $20 \mathrm{~nm}$, with a narrow range of particle-size distribution. These particles are created by a sol-gel manufacturing process [10], and the particle size and excellent dispersion remain unchanged during any further mixing and/or blending operations. Further, despite the relatively high $\mathrm{SiO}_{2}$ content of $40 \mathrm{wt}$.\%, the nano-filled epoxy resin still has a comparatively low viscosity due to the agglomerate-free colloidal dispersion of the nano-particles. The curing agent was an accelerated methylhexahydrophthalic acid anhydride, 'Albidur HE600' supplied by Nanoresins, and a stoichiometric amount was used. The mixtures were poured into release-coated moulds, and cured for 1 hour at $90^{\circ} \mathrm{C}$ followed by 2 hours at $160^{\circ} \mathrm{C}$. As an example of the basic properties of these materials [6,9], the values of the glass transition temperature, $T_{g}$, from dynamic mechanical testing and Young's modulus, E, from tensile testing of the unmodified epoxy-polymer were $153^{\circ} \mathrm{C}$ and $2.96 \mathrm{GPa}$, respectively, see Table 1 . 
The bulk sheets of the materials were machined to produce compact tension specimens for fracture and cyclic-fatigue testing. For both types of test, natural cracks were generated by tapping a new razor-blade into the machined notch [11]. The fracture toughness, $K_{I c}$, was measured at a displacement rate of $1 \mathrm{~mm} / \mathrm{min}$, following the procedures described in the standard [11]. The fatigue tests were conducted in displacement control, with a displacement ratio, $\delta_{\min } / \delta_{\max }$, of 0.5 . Sinusoidal loading was used, with a frequency of $5 \mathrm{~Hz}$. The rate of cyclic-fatigue growth per cycle, $\mathrm{d} a / \mathrm{d} N$, was measured [12] as a function of the range of applied stress-intensity factor, $\Delta K_{I}$.

\section{Results}

The results are summarised in Table 1, where the values of the glass transition temperature, $T_{g}$, modulus, $E$, and the fracture toughness, $K_{I c}$, for the various formulations are shown. The addition of the nano-particles did not affect the glass transition temperature, but increased the modulus as expected [9]. The toughness of the epoxy polymers increased steadily as the concentration of the nano-silica particles was increased. The reasons for this observation have been studied, and reported in a recent paper [9]. In this work, the fracture surfaces were inspected using scanning electron and atomic force microscopy, and the results were compared to various toughening mechanisms proposed in the literature. The toughening mechanisms of crack pinning, crack deflection and immobilised polymer were discounted. The microscopy studies showed evidence of debonding of the nano-silica particles and subsequent plastic void growth in the epoxy polymer. A theoretical model of plastic void growth was used to confirm that this mechanism was indeed most likely to be responsible for the increased toughness that was observed due to the addition of the nano-silica particles.

Considering the cyclic-fatigue work, Figure 2 shows typical results for the unmodified epoxy polymer and for the material containing $7.8 \mathrm{wt}$.\% of nano-silica particles. There are several noteworthy points. Firstly, for both materials there is a region where there is a linear relationship between the logarithmic crack growth rate per cycle, $d a / d N$, versus the logarithmic range of applied stress-intensity factor, $\Delta K_{I}$, from the cyclic-fatigue tests, i.e. the 'Paris Law region'. Secondly, there is a clearly identifiable 'threshold region', i.e. a value of $\Delta K_{I}$, denoted $\Delta K_{t h}$, below which no cyclic-fatigue crack growth will occur, again for both polymers. This threshold value, $\Delta K_{t h}$, is a very useful parameter for both (a) material development and selection, and (b) the design engineer. Thirdly, the cyclic-fatigue properties of the epoxy polymer are clearly enhanced by the presence of the nano-silica particles, and that the value of $\Delta K_{t h}$ is increased significantly due to the addition of 7.8 wt.\% of nano-silica. 
Indeed, Figure 3 shows the range of applied stress-intensity factor at threshold, $\Delta K_{t h}$, from the cyclic-fatigue tests versus the fracture toughness, $K_{I c}$, for all the materials studied. It can be clearly seen that the value of $\Delta K_{t h}$ increases steadily as the toughness, $K_{I c}$, rises, i.e. as the concentration of nano-silica particles is increased.

\section{Conclusions}

The introduction of nano-silica particles into the epoxy polymer has increased both the initial toughness, as measured the fracture toughness, $K_{I c}$, and also significantly improved the cyclicfatigue behaviour of the epoxy polymer. Thus, the significant increases recorded in the values of the range of applied stress-intensity factor at threshold, $\Delta K_{t h}$, from the cyclic-fatigue tests for the nano-silica modified materials are very noteworthy, since these increases are accompanied by significant improvements being recorded in the initial toughness.

\section{Acknowledgments}

The authors wish to thank the Henkel Corporation for financial support and Nanoresins AG for the supply of material. 


\section{References}

1. $\quad$ R.S. DRAKE and A.R. SIEBERT, SAMPE Quart. 6(4) (1975) 11.

2. A.J. KINLOCH, S.J. SHAW, D.A. TOD and D.L. HUNSTON, Polymer 24 (1983) 1341.

3. $\quad$ A.F. YEE and R.A. PEARSON, J. Mater. Sci. 21 (1986) 2462.

4. $\quad$ A.J. KINLOCH, Materials Research Society Bulletin 28 (2003) 445.

5. A.J. KINLOCH, J.H. LEE, A.C. TAYLOR, S. SPRENGER, C. EGER and D. EGAN, J. Adhesion 79 (2003) 867.

6. A.J. KINLOCH, R.D. MOHAMMED, A.C. TAYLOR, C. EGER, S. SPRENGER, and D. EGAN, J. Mater. Sci. 40 (2005) 5083.

7. A.J. KINLOCH, R.D. MOHAMMED, A.C. TAYLOR, S. SPRENGER, and D. EGAN, J. Mater. Sci. 41 (2006) 5043.

8. B. WETZEL, P. ROSSO, F. HAUPERT and K. FRIEDRICH, Engng. Fracture Mech., 73 (2006) 2375.

9. B.B. JOHNSEN, A.J. KINLOCH, R.D. MOHAMMED, A.C. TAYLOR, and S. SPRENGER, Polymer 48 (2007) 530.

10. S. SPRENGER, C. EGER, A.J. KINLOCH, J.H. LEE, A.C. TAYLOR and D. EGAN, Adhäsion, Kleben \& Dichten 2003(3) (2003) 24.

11. ISO 13586, "Plastics - Determination of Fracture Toughness $\left(G_{I c}\right.$ and $\left.K_{I c}\right)$ - Linear Elastic Fracture Mechanics (LEFM) Approach” (ISO, Geneva, CH, 2000).

12. ASTM E647, "Standard Test Method for Measurements of Fatigue Crack Growth Rates" (ASTM, Philadelphia, USA, 2005). 
Table 1. The formulations employed, their glass transition temperature [9], modulus [6] and fracture toughness.

\begin{tabular}{|c|c|c|c|}
\hline wt. \% nano-SiO & $T_{q}\left({ }^{\circ} \mathrm{C}\right)$ & $E(G P a)$ & $K_{I c}\left(\mathrm{MPa} \mathrm{m}^{1 / 2}\right)$ \\
\hline 0.0 & 153 & 2.96 & 0.51 \\
\hline 4.0 & 152 & 3.20 & 0.65 \\
\hline 7.8 & 154 & 3.42 & 0.79 \\
\hline 14.8 & 152 & 3.60 & 0.83 \\
\hline 20.2 & 150 & 3.85 & 0.88 \\
\hline
\end{tabular}




\section{Figure Captions}

Figure 1 Atomic force microscopy image showing the excellent dispersion of the $\mathrm{SiO}_{2}$ nanoparticles in the cured epoxy polymer containing $14.8 \mathrm{wt} . \%$ of nano-silica particles.

Figure 2 Logarithmic crack growth rate per cycle, $d a / d N$, versus logarithmic range of applied stress-intensity factor, $\Delta K_{I}$, from the cyclic-fatigue tests for the unmodified epoxy and a nano-silica toughened epoxy containing 7.8 wt.\% of nano-silica particles.

Figure 3 The range of applied stress-intensity factor at threshold, $\Delta K_{t h}$, from the cyclic-fatigue tests versus the fracture toughness, $K_{I c}$. 


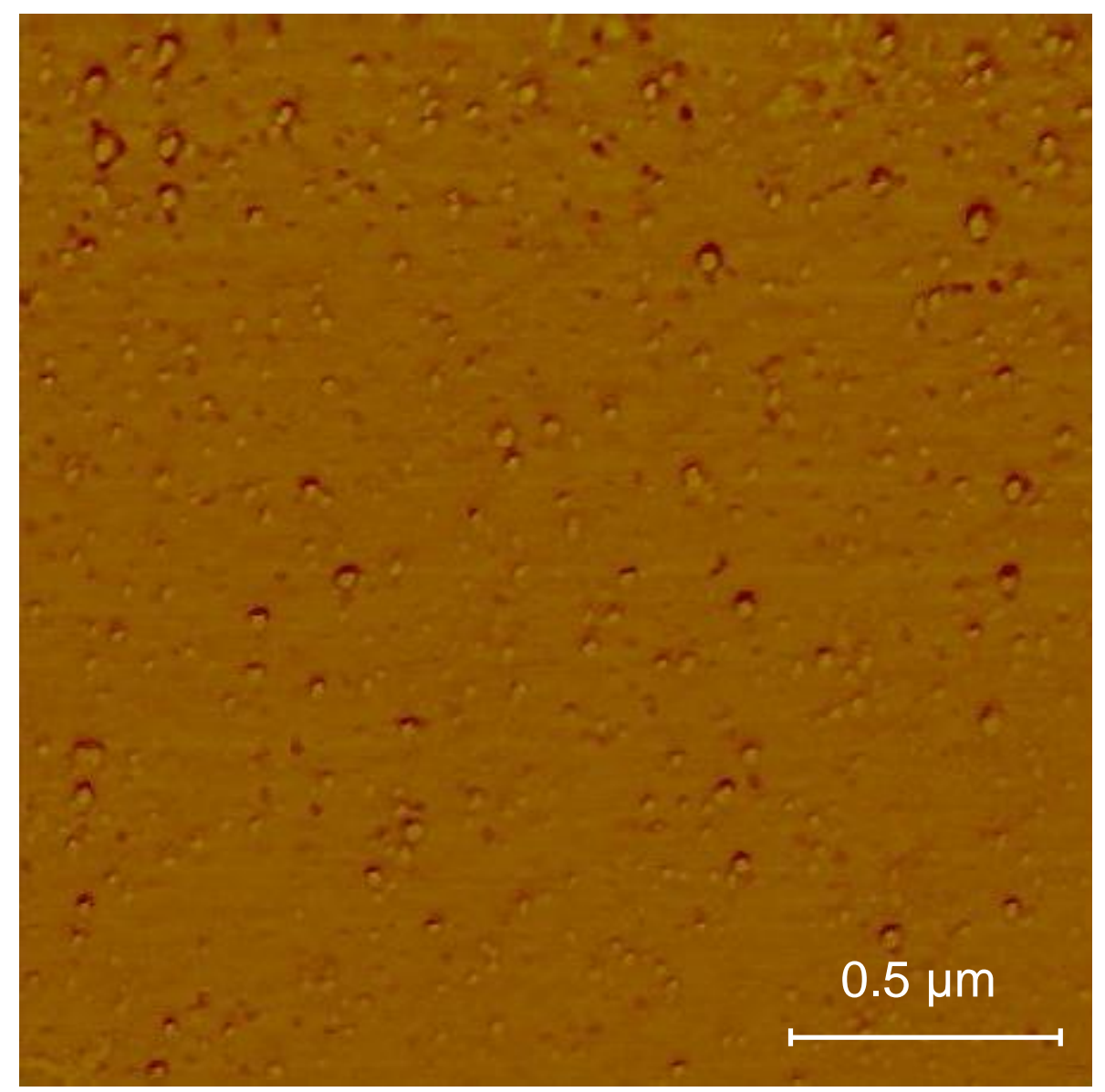

Figure 1 Atomic force microscopy image showing the excellent dispersion of the $\mathrm{SiO}_{2}$ nanoparticles in the cured epoxy polymer containing $14.8 \mathrm{wt} \% \%$ of nano-silica particles. 


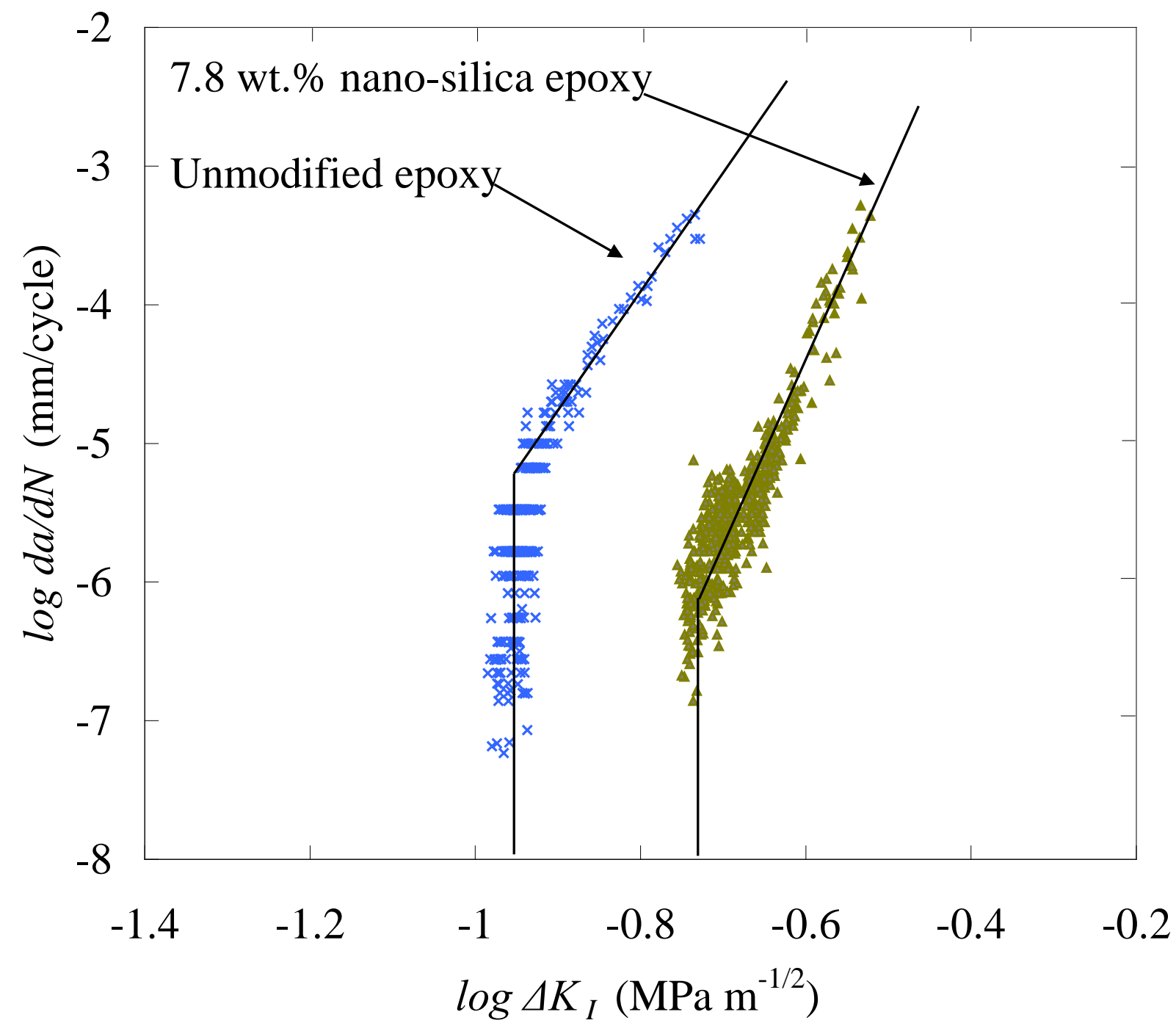

Figure 2 Logarithmic crack growth rate per cycle, $d a / d N$, versus logarithmic range of applied stress-intensity factor, $\Delta K_{I}$, from the cyclic-fatigue tests for the unmodified epoxy and a nano-silica toughened epoxy containing $7.8 \mathrm{wt}$ \% of nano-silica particles. 


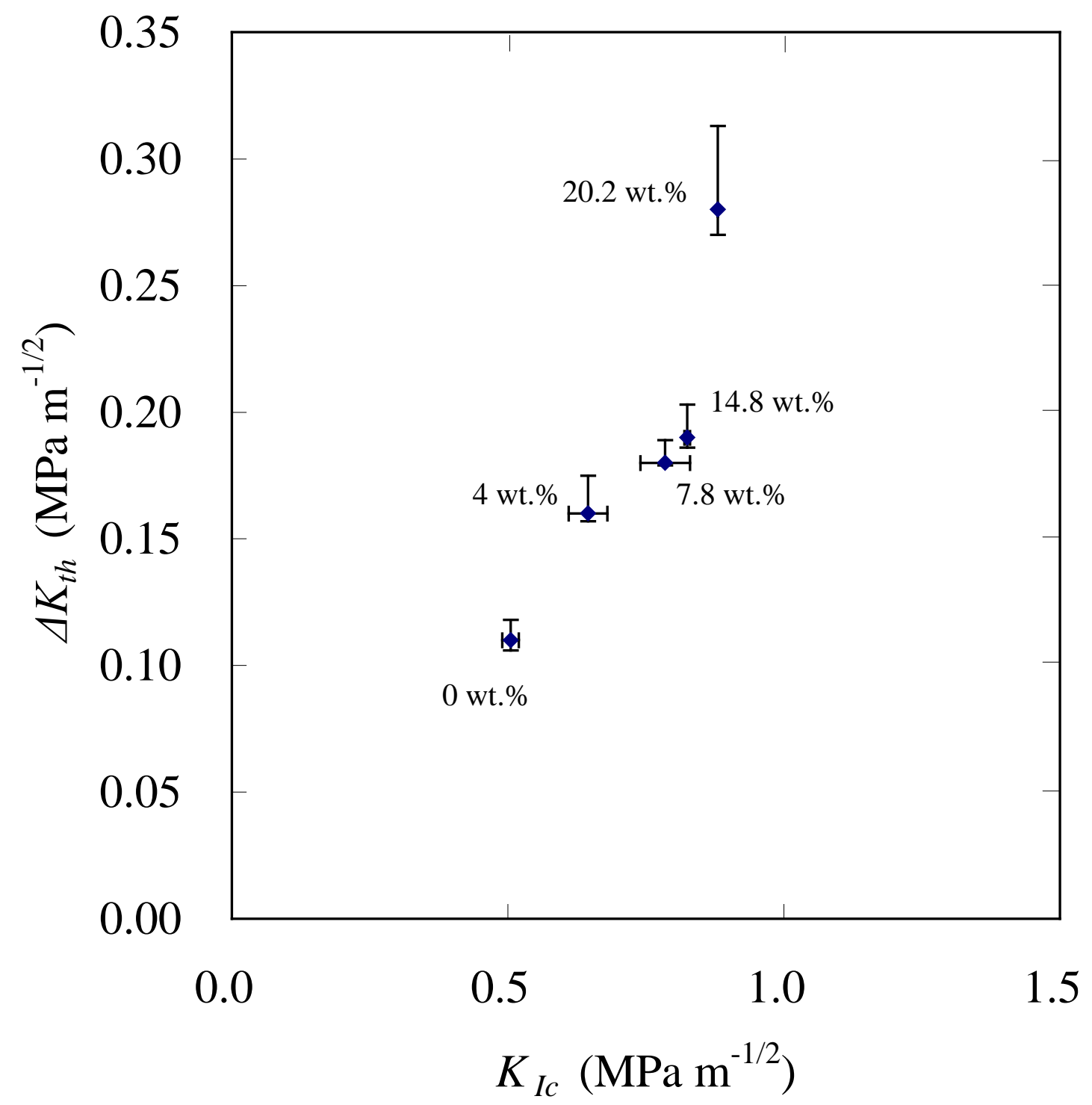

Figure 3 The range of applied stress-intensity factor at threshold, $\Delta K_{t h}$, from the cyclic-fatigue tests versus the fracture toughness, $K_{I c}$. 